\section{Male circumcision and HIV prevention: ethical, medical and public health tradeoffs in low-income countries}

\section{Stuart Rennie, Adamson S Muula, Daniel Westreich}

\section{Ethical challenges surrounding the implementation of male circumcision as an HIV prevention strategy}

$\mathrm{R}$ searchers have been exploring the possibility of a correlation between male circumcision and lowered risk of HIV infection almost since the beginning of the HIV/AIDS epidemic. ${ }^{1}$ Results from a randomised controlled trial in South Africa in 2005 indicate that male circumcision protects men against the acquisition of HIV through heterosexual intercourse, ${ }^{2}$ confirming the findings from 20 years of observational studies. ${ }^{3}$ Circumcised men in the South African trial were $60 \%$ (95\% CI $32 \%$ to $76 \%$ ) less likely to acquire HIV than their uncircumcised counterparts. A mathematical modelling study, based on the South African trial, estimates that the practice of male circumcision could avert two million new HIV infections and 300000 HIV-related deaths over the next 10 years in sub-Saharan Africa. ${ }^{4}$ More recently, two randomised controlled trials in Kisumu, Kenya and Rakai, Uganda showed, respectively, $53 \%$ and $48 \%$ reductions in HIV acquisition among circumcised men than uncircumcised men in the trial. ${ }^{5}$ These results strongly suggest that male circumcision could play an important role in the struggle against the continued rise in new HIV infections. However, as observers noted at the 2006 XVI International AIDS Conference in Toronto, Canada, excitement about the potential epidemiological impact has overshadowed the debate over the difficult translation of research on male circumcision, into policy and practice. ${ }^{6}$ Similar calls for caution have been raised before and elsewhere. ${ }^{7}$

The topic of male circumcision carries an enormous amount of ethical baggage. Male infants, worldwide, are circumcised for various medical, social and/or religious reasons. Circumcision is a cultural act and a surgical procedure; medical reasons are not the only reasons to circumcise that people have found and continue to find as compelling. Benatar and Benatar ${ }^{9}$ have argued that-when performed in adequate clinical settingsneonatal circumcision does not threaten the health and safety of a child to an extent that justifies society over-riding a parent's right to decide what is in their child's best interest on the basis of their own social or religious values. Others strongly object by arguing (in part) that in the absence of a defined and substantial benefit, the medical principle of "do no harm" should prevail. ${ }^{10} 11$

The ethics of male circumcision cannot be considered apart from its historical context. In the past, medical communities in industrialised countries have recommended male circumcision to prevent or treat several health conditions. ${ }^{12}$ Some recommendations-such as the use of circumcision to treat mental illness, ${ }^{13}$ tuberculosis, $^{14}$ excessive masturbation ${ }^{15}$ and schistosomiasis ${ }^{16}$ - turned out to be clearly mistaken. Although there is evidence of associations between male circumcision and lowered risk of penile cancer, ${ }^{17}$ acquisition of syphilis, ${ }^{18}$ urinary tract infections ${ }^{19}$ and penile human papillomavirus infection, ${ }^{20}$ these benefits for men are of questionable relevance: the absolute risk of penile cancer is negligible ( 1 in 100000 in the US ${ }^{21}$ ), and there are generally more cost-effective and lowerrisk ways of treating these infections than circumcision. Although recent studies indicate that male circumcision may reduce the risk of cervical cancer ${ }^{22}$ and chlamydia infection ${ }^{23}$ in their female partners, the fact remains that for many decades, in Western countries (particularly in the US), neonatal circumcision has been routinely performed in hospitals largely for sociocultural and religious reasons, as the medical and public health justifications for the intervention were weak. $^{24}$

The new findings on male circumcision and HIV alter the terms of the debate over the ethics of male circumcision. The results of the trials in South Africa, Kenya and Uganda, all suggest that male circumcision could offer important clinical and public health benefits for individuals and populations in the high-HIV prevalence settings with heterosexually driven epidemics. Disagreements persist about the justification of promoting male circumcision as a part of the HIV prevention policy, on the basis of current scientific evidence. These disagreements hinge on whether a similarly high degree of protective effect can be replicated, over the long term, outside the context of a carefully controlled clinical trial. Some argue that health policies always involve risk, and HIV/AIDS is an urgent public health emergency, warranting and even demanding bold measures..$^{25}$ However, the long term and/or absolute reduction in HIV transmission risk via male circumcision remains uncertain and partly depends on population prevalence. There is room for discussion about the justification of implementing male circumcision for HIV prevention before its overall health impact has been fully quantified.

In this article, we will not focus on the scientific issues surrounding the current research on male circumcision. We will work from the perspective that the current evidence from studies in three sub-Saharan countries indicates that male circumcision is (at least) promising as an HIV-prevention strategy-that is, in public health terms, male circumcision is as promising as an HIV vaccine or preexposure prophylactic drug that showed a similar short-term protective effect in a series of randomised controlled trials. Using the age of circumcision as a vantage point, this article develops a new framework to understand the complex array of ethical and practical challenges faced by this controversial way of preventing HIV in high prevalence, lowincome countries, particularly in subSaharan Africa.

\section{NEONATAL CIRCUMCISION AND HIV PREVENTION}

In this debate, many issues can be organised around a central question: if male circumcision is considered as an intervention to help reduce the HIV acquisition rates, when in the male lifecycle should health authorities recommend that circumcision be performed? There seem to be three obvious points: soon after birth, just before sexual debut and at some point after sexual debut (sexual adulthood). Each point has highly interconnected advantages and disadvantages from medical, public health and ethical perspectives (table 1). Although promoting male circumcision at all ages simultaneously is possible in principle, limits of human and material resources in the health systems 
Table 1 Ethical, medical and public health perspectives on male circumcision

\begin{tabular}{|c|c|c|c|}
\hline \multirow[b]{2}{*}{ Ethical issue } & \multicolumn{3}{|c|}{ Age group targeted for male circumcision } \\
\hline & Infants & Pre-adolescent & Adult \\
\hline $\begin{array}{l}\text { Consent } \\
\text { Feasibility }\end{array}$ & $\begin{array}{l}\text { Parental (proxy) consent only } \\
\text { High: integration in existing } \\
\text { reproductive care }\end{array}$ & $\begin{array}{l}\text { Assent and parental consent } \\
\text { Low: possible difficulties in reaching } \\
\text { target population }\end{array}$ & $\begin{array}{l}\text { Informed consent for competent adults } \\
\text { Low: infrequent use of health services by male } \\
\text { adults }\end{array}$ \\
\hline Risk compensation & Not significant & Significant & Significant \\
\hline Epidemiological impact & Distal: $15-20$ years & Potentially immediate & $\begin{array}{l}\text { Potentially immediate, but lost opportunities for } \\
\text { prevention among sexually active adults }\end{array}$ \\
\hline HIV testing & Not applicable & \multirow{2}{*}{\multicolumn{2}{|c|}{$\begin{array}{l}\text { Potential stigma, inadvertent disclosureAppropriateness of circumcision when the adult } \\
\text { of parental status } \\
\text { is HIV positive } \\
\text { High: demand may require substantialHigh: demand may require substantial } \\
\text { investment and involvement of investment and involvement of traditional healers } \\
\text { traditional healers }\end{array}$}} \\
\hline Burden on health services & $\begin{array}{l}\text { Lowest: integration into existing } \\
\text { reproductive care }\end{array}$ & & \\
\hline
\end{tabular}

of developing countries may necessitate a less ambitious approach.

As a measure of protection against HIV infection, circumcising soon after birth could have some important advantages. Some studies indicate that the protective effect is greater when circumcision takes place early in a man's life, presumably due to the thickening of the skin on the head of the penis. ${ }^{26}$ Another possible advantage is cost: neonatal circumcision could be integrated into existing reproductive health clinics, postnatal care services or programmes to prevent mother-to-child transmission of HIV. Neonatal circumcision also avoids lost days from school and work, associated with circumcision at later ages.

Circumcising at an early age can also avoid the thorny problem of risk compensation. Risk compensation is the common psychological phenomenon of an increase in risky behaviour due to a decrease in perceived risk. ${ }^{27}$ Just as some car drivers tend to take more risks on the road when they are wearing a seatbelt, ${ }^{28}$ men may engage more often in unsafe sex if they believe circumcision protects them from acquiring HIV. However, if circumcision takes place at an early age, it is unlikely that the intervention would have an impact on a man's HIV risk perception when he engages in sexual relations more than a decade later.

Although neonatal male circumcision has significant cost and public health advantages, the ethics of neonatal circumcision remain more complicated. As with other controversial paediatric interventions, the issues revolve largely around the issues of autonomy and consent. Neonatal circumcision is a form of non-consensual surgery, and in the US, autonomy as a principle in medical ethics historically emerged from a legal case of non-consensual surgery. ${ }^{29}$ Opponents of neonatal circumcision typically argue that surgical removal of a healthy child's foreskin without his informed consent is always wrong. Although parents regularly practice proxy decision-making for their children when choosing other (and sometimes invasive) therapeutic interventions, and some other prevention measures are mandatory (ie, vaccinations), opponents of neonatal circumcision commonly argue that parents should wait until the child is old enough to make an autonomous decision. ${ }^{11}$

This autonomy-centred argument is problematic for several reasons. First, it would be unreasonable from public health and ethical perspectives to permit childhood vaccinations, such as those, against diphtheria, tetanus and pertussis, while universally condemning neonatal male circumcision, if (as research may show) the neonatal male circumcision can offer long-term vaccine-level protection against HIV transmission, and if the child is living in a high-HIV-prevalence setting. In that case, the autonomycentred argument would both exclude the use of an intervention with a potentially substantial beneficial populationlevel health effect, and restrict commonly accepted parental rights to choose what they believe is in their child's best interest. Furthermore, studies indicate that the perception of risk among young men at sexual debut is highly distorted. ${ }^{30}$ Many young men could refuse circumcision during adolescence due to not perceiving themselves at risk for HIV infection. Given the vagaries of adolescent decision-making and the gravity of the decision, parents may reasonably wish to choose circumcision for their infants rather than wait for their sons to decide for themselves.

We should note some important disadvantages to neonatal circumcision as well. Circumcising male infants now, can only have an impact on the HIV epidemic more than a decade later. Other, less invasive and more effective methods of HIV prevention such as topical microbicides for males, pre-exposure prophylactic drugs or HIV vaccines could be discovered before the children reach sexual debut. In this case, neonatal circumcision would lack some of its intended medical justification by the time the intervention began to exert a protective effect.

In addition, questions can be raised about the cultural acceptability of neonatal circumcision. Many ethnic groups in Africa circumcise, but most do so in early adolescence, because circumcision is often (particularly in rural areas) practised as part of a boy's rite of passage into manhood. ${ }^{31}$ Among currently circumcising groups, circumcising soon after birth could dramatically alter the social, psychological and cosmological dimensions of the traditional process of circumcision, and some communities may be reluctant to tolerate this degree of cultural change to stem new HIV infections. It could be easier for groups that do not currently circumcise to accept non-ritualised, neonatal circumcision. In Botswana, circumcision practices were once rites of passage, but these were largely abandoned in the 19th and 20th centuries by the influence of western medical missionaries. A recent cross-sectional survey in Botswana indicates that $55 \%$ of parents believe that if male circumcision offers protection against sexually transmitted diseases (including HIV), it should be performed before the age of 6 years, and $90 \%$ felt it should be performed in a hospital setting. ${ }^{32}$ Implementation of neonatal male circumcision as an HIV-prevention strategy cannot be ethically sound without community-based research into the acceptability of different approaches among currently circumcising and non-circumcising groups.

\section{PREADOLESCENT CIRCUMCISION AND HIV PREVENTION}

As mentioned above, male circumcision in Africa is typically practised as a rite of passage from boyhood to manhood. Therefore, one might assume that the 
feasibility and acceptability of implementing male circumcision as an HIVprevention strategy just before adolescence would be high among many currently circumcising groups, because it simply involves incorporating a new rationale and HIV-prevention messages into an existing practice. A model that integrates HIV-prevention into pre-adolescent circumcision traditions (seize the day) has been successfully implemented on a small scale in eastern Kenya. ${ }^{33}$

However, large-scale preadolescent circumcision presents serious challenges. First, some aspects of traditional practices will need to be modified in order to align them with the goals of HIV prevention. Some traditional circumcising techniques-such as the use of the same ritual knife among a number of initiates - themselves pose HIV transmission risk. ${ }^{31}$ In some groups, sexual activity is encouraged soon after circumcision in order to complete the transition to manhood ${ }^{34}$; in Kenya there are reports of young men visiting sex workers for this purpose. ${ }^{35}$ Because the penis will still be healing, sex soon after circumcision may put an individual at a greatly increased risk of HIV acquisition; in this situation, cultural norms may run counter to HIVprevention messages, making the latter less effective. Similarly, conflicts may emerge between the traditional meaning given to the pain of circumcision (as a test of character and strength) and the medical commitment to pain reduction. Medicalising circumcision may change its meaning to an extent that some local communities may resist.

On a more fundamentally ethical note, we have the vexing issue of assent: the older the child is, the more appropriate it seems to ask for his agreement-particularly when considering an irreversible surgical procedure on his genitalia. However, some parents and guardians may be dissuaded from having their son/ sons circumcised, as an assent process would involve conveying information about sexuality and HIV/AIDS to the young person. Obtaining assent also raises the thorny question of what to do if an adolescent refuses to assent, but the parents want the circumcision to take place, or the reverse. Indeed, the very notion of obtaining assent for circumcision may be culturally alien. Typically, young members of a tribe are told that circumcision is simply part of becoming a man, and stigma can be attached to nonparticipation. Agreement to the procedure is typically assumed and not solicited. Those promoting circumcision at preadolescence among circumcising groups will need to be sensitive to the legal, ethical and cultural implications of seeking or not seeking assent.
What about pre-adolescent circumcision among currently non-circumcising groups? There are at least three possibilities: introducing (safe) circumcision rituals among non-circumcising groups; promoting non-ritualised, medical circumcisions at clinics; or a combination of both approaches. Many tribal groups in Africa seem to have practised circumcision in the past, and therefore preadolescent male circumcision could be reintroduced as a lapsed indigenous rite rather than an unprecedented and alien practice. ${ }^{31}$ But, even traditional healers seem to support conducting male circumcision at hospitals and clinics when the purpose is to prevent sexually transmitted diseases, ${ }^{36}$ and there are recent anecdotal reports from Swaziland (where circumcision was abandoned by royal decree in the late 1880s) of mothers taking their teenage sons for circumcision at clinics. ${ }^{37}{ }^{38}$ For some populations, it may be better to promote purely medical circumcision at preadolescence (or, for that matter, among neonates) than to conjure up a ritual from the past.

Circumcising at preadolescence has practical advantages and disadvantages relative to neonatal circumcision. Offering circumcision to boys at schools and youth centres may lead to lower uptake of services than promoting neonatal circumcision at reproductive clinics Boys from impoverished families, who do not attend school, could be excluded and some communities (particularly rural ones) may not have youth centres. In addition, risk compensation could be a serious concern in this population, if circumcision reinforces their natural teenage or preteenage sense of being at a very low risk for HIV infection and more general invulnerability.

On the other hand, circumcising at preadolescence could realise benefits quickly by immediately affecting the rate of new HIV infections among a population that is at a high risk in much of subSaharan Africa. Acting as a counterbalance to the potential for risk compensation is that, depending on when and how it is offered, the surgical event may provide an excellent opportunity for HIV counselling and education among a vulnerable but not yet sexually active population.

\section{ADULT CIRCUMCISION AND HIV PREVENTION}

Adult male circumcision has some advantages over neonatal and adolescent circumcision. Unlike neonatal circumcision and like adolescent circumcision, the procedure could have immediate individual and epidemiological benefits. By this approach, one also avoids the complexities of assent and parental consent involved in circumcising boys. Even the most fervent anti-circumcision advocates do not oppose a competent and well-informed adult choosing to get circumcised.

However, concentrating circumcision efforts on adults who have already been sexually active means missed opportunities for HIV prevention. There is also the issue of which adults should be offered circumcision services when health budgets are limited. Should men who are most likely to acquire and transmit HIVtruck drivers, soldiers and teachers-be specifically targeted by circumcision services? Public health efficiency could conflict with the rights of individuals if circumcised individuals among non-circumcising groups end up being stigmatised as being at special risk for HIV. However, avoiding targeting of a population by gradually routinising circumcision in local healthcare systems would probably be more costly and less efficient in terms of the number of interventions needed to prevent an HIV infection and reduce the speed of epidemiological impact. Policy makers opting for adult circumcision will have to negotiate difficult efficiency-fairness trade-offs. In addition, circumcising at adulthood raises the likelihood of some degree of risk compensation and sexual disinhibition, so strategies to combat perceptions of lower risk among newly circumcised adults would have to be pursued vigorously if the benefits of circumcision at an epidemiological level are not to be nullified out by increases in high-risk behaviour.

The general goals of HIV prevention would be well served by integrating male circumcision services with HIV testing. As adult men in sub-Saharan Africa (as elsewhere) do not present frequently at health clinics, provision of circumcision services could be an opportunity to offer HIV testing along with other health services. Offering HIV tests to adult men also seems to be ethically appropriate (if not ethical obligatory), because only if the man knows what his serostatus is he may be truly informed about how he may stand to benefit (personally) from the procedure. But connecting circumcision with HIV testing also raises some ethical issues. What should be done for men who test positive in the process of seeking circumcision services? Should male circumcision be offered only in post-test counselling to men who test negative for HIV? Should men who test positive for HIV be advised to get circumcised anyway, on the possibility that circumcision may directly or indirectly reduce their infectivity to women? Or should these 
men simply be told to use condoms or practice abstinence? These ethical problems cannot be avoided by integrating HIV testing with preadolescent circumcision: parents may not agree to have their male child circumcised if it is linked with HIV testing, and the result of the test may put the minor in harm, particularly if a positive test result of a sexually inactive adolescent inadvertently discloses the status of the parent(s).

Finally, a cross-cutting issue about safety, cost and equity. If circumcision is performed at any age, in any context, it should be done safely. However, safe circumcision costs money. Estimates vary, but the cost of male circumcision will be prohibitive for those who are most economically vulnerable in low-resource countries. It is plausible that circumcisions in clinical settings-with effective anaesthesia, postoperative care and counseling-will initially be affordable only for relatively privileged groups in subSaharan Africa. The less privileged groups may only be able to access cheaper circumcision services and face higher complication risks and potential risk of HIV infection. Popular demand could also give rise to self-appointed circumcisers offering dubious services at low prices. If the demand for circumcision services overwhelms the capacity of local clinics and hospitals, it may well be wise to train traditional healers to perform hygienic circumcision in non-clinical settings, but training, supplies and transport also cost money. If questions are not resolved about sustainable payment of direct and opportunity costs of circumcision, communities may be divided into those who can afford this novel form of HIV prevention and those who cannot.

\section{FUTURE ETHICAL CHALLENGES AND RECOMMENDATIONS}

The above discussion has only touched on some of the ethical challenges surrounding the implementation of male circumcision as an HIV-prevention strategy. Some others challenges include: conflicts between circumcision as medical intervention and marks of ethnic identity; current scarcity of formal economic justifications for circumcision relative to other HIV-prevention strategies; potential burdens of the intervention on already fragile health systems; differences between results of acceptability studies and actual circumcision acceptance; the impact of male circumcision promotion on the women's ability to negotiate condom use with circumcised partners; perception of ethical double standards if the policy is targeted exclusively at resource-poor countries; and potential confusion with policies forbidding female genital mutilation.

Given the results of the recent clinical trial, and the steady rise in new HIV infections in resource-poor countries, it would be unethical to not seriously consider one of the most promisingalthough also one of the most controversial-new approaches to HIV-prevention in the 25-year history of the epidemic. Seriously considering the practice of male circumcision involves avoiding the extremes of (1) a flat dismissal of this approach on the basis of a rejection of male circumcision as a form of genital mutilation and (2) an overly optimistic interpretation of the recent randomised controlled trials that downplay the scientific and, especially, social uncertainties, and assumes that translating circumcision research into policy and practice could be straightforward and risk free.

If male circumcision is to be promoted in regions of high HIV prevalence, the following basic ethical conditions must be put in place: sufficient material and human resources to perform circumcisions safely; careful monitoring of the quality of follow-up care; international and national committments to low-cost circumcisions to facilitate equitable access; flexible policies informed by concerns of local communities regarding if when, where and how circumcisions should be performed; careful attention to the consent process and sustained condom promotion to minimise the risk of behavioural disinhibition; monitoring of circumcision promotion messages to ensure that prospective clients are aware of potential benefits and limits; education of women and girls about male circumcision initiatives to combat potentially tragic misconceptions; and conformity of circumcision policies with international norms (such as the Siracusa principles ${ }^{39}$ ) limiting the extent to which individual rights can be infringed to promote the public good.

Future initiatives to promote male circumcision as part of comprehensive HIV prevention policies are likely to lose public trust and effectiveness if they are not grounded in respect for persons, social justice, human rights and community values. Without an open-minded dialogue on these ethical challenges between the Western medical establishments and international organisations promoting male circumcision, and the people and governments for whom the intervention may be most appropriate, a potentially vital contribution to the fight against HIV/AIDS could be squandered.

\section{ACKNOWLEDGEMENTS}

SR is partly funded by a NIH/Fogarty Bioethics International Research Ethics and Curriculum
Development Award (Strengthening Bioethics Capacity and Justice in Health: R25-TW 7098).

J Med Ethics 2007;33:357-361.

doi: 10.1136/jme.2006.019901

\section{Authors' affiliations}

Stuart Rennie, Departments of Dental Ecology and Social Medicine, University of North

Carolina at Chapel Hill, Chapel Hill, North Carolina, USA

Adamson S Muula, Department of Community Health, University of Malawi, College of Medicine, Blantyre, Malawi

Daniel Westreich, Department of Epidemiology, School of Public Health, University of North Carolina at Chapel Hill, Chapel Hill, North Carolina, USA

Correspondence to: Dr S Rennie, School of Dentistry, University of North Carolina at Chapel Hill, Chapel Hill, NC 27599-7450, USA; stuart_rennie@unc.edu

\section{Received 15 November 2006}

Revised 9 January 2007

Accepted 31 January 2007

Competing interests: None.

\section{REFERENCES}

1 Fink AJ. A possible explanation for heterosexual male infection with AIDS. New Engl J Med 1986;315:1167.

2 Auvert B, Taljaard D, Lagarde E, et al. Randomized controlled intervention trial of male circumcision for reduction of HIV infection risk: the ANRS 1265 trial. PLoS Med 2005; 12:298.

3 Siegfried N, Muller M, Volmink J, et al. Male circumcision for prevention of heterosexual acquisition of HIV in men. Cochrane Database Syst Rev.lssue 3. Oxford: CD003362, 2003.

4 Williams BG, Lloyd-Smith JO, Gouws E, et al. The potential impact of male circumcision on HIV in subSaharan Africa. PloS Med 2006;3:e262.

5 National Institute of Allergy and Infecticious Disease. Adult male circumcision significantly reduces risk of acquiring HIV: trials Kenya and Uganda stopped early. Press release. http:// www3.niaid.nih.gov/news/newsreleases/2006/ AMC12_06.htm (accessed 22 Mar 2007).

6 Nolen S. Male circumcision not an easy answer for HIV. Toronto: Globe and Mail, 2006.

7 Ntozi JMP. Using circumcision to prevent HIV infection: the view of an African. Health Transit Rev 1997;7(Suppl):97-100.

8 Siegfried N. Does male circumcision prevent HIV transmission? PLoS Med 2005;2:e393.

9 Benatar M, Benatar D. Between prophylaxis and child abuse: the ethics of neonatal male circumcision. Am J Bioeth 2003;3:35-48.

10 Fox $M$, Thomson $M$. A covenant with the status quo? Male circumcision and the new BMA guidance to doctors. J Med Ethics 2005;31:463-9.

11 Hellsten SK. Rationalizing circumcision: from tradition to fashion, from public health to individual freedom - critical notes on cultural persistence of the practice of genital mutilation. J Med Ethics 2004;30:248-53.

12 Gollaher DL. Circumcision: a history of the world's most controversial surgery. New York: Basic Books, 2000.

13 Darby R. A surgical temptation: the demonization of the foreskin and the rise of circumcision in Britain. Chicago: University of Chicago Press, 2005.

14 Remondino PC. History of circumcision from the earliest times to the present: Moral and physical reasons for its performance. Philadelphia: FA Davis, 1891.

15 Hutchinson J. On circumcision as preventive of masturbation. Arch Surg 1891;2:267-8. 
16 Allen J. Bilharzia haematobia and circumcision. Lancet 1909;173:1317-20.

17 Schoen EJ, Oehrli M, Colby CJ, et al. The highly protective effect of newborn circumcision against invasive penile cancer. Pediatrics 2000;105:e36-9.

18 Cook LS, Koutsky LA, Holmes KK. Circumcision and sexually transmitted diseases. Am J Public Health 1994:84:197-201.

19 To T, Aghar M, Dick PT, et al. Cohort study on circumcision on newborn boys and subsequent risk of urinary tract infection. Lancet 1998;352:1813-16.

20 Castellsague X, Bosch FX, Munoz N, et al. Male circumcision, penile human papillomavirus infection, and cervical cancer in female partners. N Engl J Med 2002;346:1105-12.

21 Cutler SJ, Young JL Jr. Third national cancer survey: incidence data. Bethesda, MD: US Department of Health, Education, and Welfare, Public Health Service, 1975

22 Drain PK, Halperin DT, Hughes JP, et al. Male circumcision, religion, and infectious diseases: An ecologic analysis of 118 developing countries. $B M C$ Infect Dis 2006:6:172.

23 Castellsague X, Peeling RW, Francescshi S, et al. Chlamydia trachomatis infection in female partners of circumcised and uncircumcised adult men. Am J Epidemiol 2005;162:907-16.
24 Laumann EO Masi CM Zuckerman EW. Circumcision in the United States: prevalence prophylactic effects and sexual practice. JAMA 1997:277:1052-7.

25 Wise, J. Demand for male circumcision rises in a bid to prevent HIV. Bull World Health Organ 2006;84:509-11.

26 Kelly R, et al. Age of circumcision and risk of prevalent HIV infection in rural Uganda. AIDS 1999:13:399-405.

27 Cassell M, Halperin D, Shelton J, et al. Risk compensation: the Achilles' heel of innovations in HIV prevention? BMJ 2006;332:605-7.

28 Richens J, Imrie J, Copas A. Condoms and seat belts: the parallels and lessons. Lancet 2000;355:400-3.

29 Schoendorff $v$ New York Hospital (21 1 NY, 105 NE 92, 93) 1914

30 Pettifor A, Kleinschmidt I, Levin J, et al. Young people's sexual health in South Africa: HIV prevalence and sexual behaviors from a nationally representative household survey. AIDS 2005; 19:1525-34.

31 Marck J. Aspects of male circumcision in subequatorial African culture history. Health Transit Rev 1997;7(Suppl):337-59.

32 Kebaabetswe P, Lockman S, Mogwe S, et al. Male circumcision: an acceptable strategy for HIV prevention in Botswana. Sex Transm Infect 2003;79:214-19.

33 Grant E, Brown J, Michen K, et al. 'Seizing the day': right time, right place and right message for adolescent reproductive sexual health. Lessons from the Meru of Eastern province Kenya. Int J Men's Health 2004;3:189-96.

34 Muula AS, Mfutso-Bengo JM. Important but neglected ethical and cultural considerations in the fight against HIV/AIDS in Malawi. Nurs Ethics 2004; 1 1:479-88.

35 Ahlberg BM. The Mwomboko Research Project: the practice of male circumcision in central Kenya and its implications for the transmission and prevention of STD/HIV. Afr Sociol Rev 1997;1:66-81.

36 Green EC. Male circumcision and HIV infection. Lancet 2000;355:927.

37 Harrison R. Circumcision makes comeback in AIDS hit Swaziland. Reuters News Service 24 February, 2006 .

38 Timberg C. In Swaziland, science revives an old rite; circumcision makes a comeback to fight AIDS. The Washington Post. 26 December, 2005.

39 United Nations Economic and Social Council. The Siracusa Principles on the limitations and derogation provisions in the international covenant on civil and political rights. UN Document E/CN.4/ 1985/4, 1985; Annexure.

\section{Access the latest content chosen by our Editors}

BMJ Journals editors select an article from each issue to be made free online immediately on publication. Other material is free after 12 months to non-subscribers. Access the Editor's Choice from the home page-or expand your horizons and see what the other BMJ Journals editors have chosen by following the links on any BMJ Journal home page. 